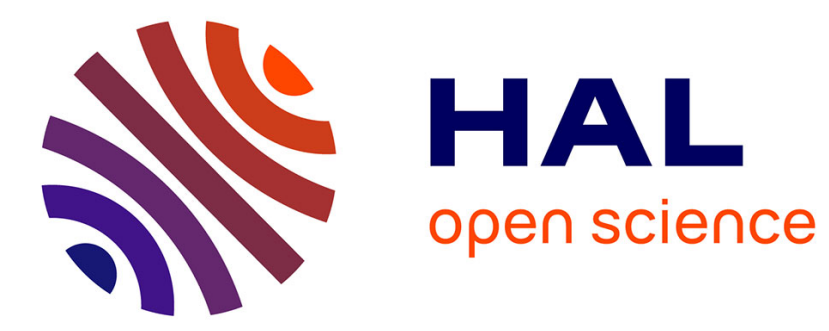

\title{
Relative effects of anthropogenic pressures, climate, and sampling design on the structure of pollination networks at the global scale
}

M. Doré, Colin Fontaine, Elisa Thébault

\section{- To cite this version:}

M. Doré, Colin Fontaine, Elisa Thébault. Relative effects of anthropogenic pressures, climate, and sampling design on the structure of pollination networks at the global scale. Global Change Biology, 2020, 10.1111/GCB.15474 . mnhn-03068210

\section{HAL Id: mnhn-03068210}

\section{https://hal-mnhn.archives-ouvertes.fr/mnhn-03068210}

Submitted on 4 Jan 2021

HAL is a multi-disciplinary open access archive for the deposit and dissemination of scientific research documents, whether they are published or not. The documents may come from teaching and research institutions in France or abroad, or from public or private research centers.
L'archive ouverte pluridisciplinaire HAL, est destinée au dépôt et à la diffusion de documents scientifiques de niveau recherche, publiés ou non, émanant des établissements d'enseignement et de recherche français ou étrangers, des laboratoires publics ou privés.

$$
\text { Copyright }
$$




\title{
Relative effects of anthropogenic pressures, climate, and sampling design on the structure of pollination networks at the global scale
}

\author{
Maël Doré ${ }^{1,2,3}$ | $\mid$ Colin Fontaine $^{2}$ | Elisa Thébault ${ }^{3}$
}

\begin{abstract}
${ }^{1}$ Institut de Systématique, Evolution, Biodiversité, MNHN-CNRS-Sorbonne Université-EPHE-Université des Antilles, Muséum national d'Histoire naturelle de Paris, Paris, France

${ }^{2}$ Centre d'Ecologie et des Sciences de la Conservation, UMR 7204 MNHN-CNRSSorbonne Université, Muséum national d'Histoire naturelle de Paris, Paris, France

${ }^{3}$ Sorbonne Université, CNRS, IRD, INRAE, Université Paris Est Créteil, Institute of Ecology and Environmental Sciences of Paris (iEES-Paris), Paris, France
\end{abstract}

\section{Correspondence}

Maël Doré, Institut de Systématique, Evolution, Biodiversité, Muséum national d'Histoire naturelle de Paris, 43 Rue Buffon, 75005 Paris, France.

Email: mael.dore@gmail.com

Funding information

Agence Nationale de la Recherche, Grant/ Award Number: ANR-14-CE02-0012 \& ANR-18-CE02-0010; French Ministry of Research

\begin{abstract}
Pollinators provide crucial ecosystem services that underpin to wild plant reproduction and yields of insect-pollinated crops. Understanding the relative impacts of anthropogenic pressures and climate on the structure of plant-pollinator interaction networks is vital considering ongoing global change and pollinator decline. Our ability to predict the consequences of global change for pollinator assemblages worldwide requires global syntheses, but these analytical approaches may be hindered by variable methods among studies that either invalidate comparisons or mask biological phenomena. Here we conducted a synthetic analysis that assesses the relative impact of anthropogenic pressures and climatic variability, and accounts for heterogeneity in sampling methodology to reveal network responses at the global scale. We analyzed an extensive dataset, comprising 295 networks over 123 locations all over the world, and reporting over 50,000 interactions between flowering plant species and their insect visitors. Our study revealed that anthropogenic pressures correlate with an increase in generalism in pollination networks while pollinator richness and taxonomic composition are more related to climatic variables with an increase in dipteran pollinator richness associated with cooler temperatures. The contrasting response of species richness and generalism of the plant-pollinator networks stresses the importance of considering interaction network structure alongside diversity in ecological monitoring. In addition, differences in sampling design explained more variation than anthropogenic pressures or climate on both pollination networks richness and generalism, highlighting the crucial need to report and incorporate sampling design in macroecological comparative studies of pollination networks. As a whole, our study reveals a potential human impact on pollination networks at a global scale. However, further research is needed to evaluate potential consequences of loss of specialist species and their unique ecological interactions and evolutionary pathways on the ecosystem pollination function at a global scale.
\end{abstract}

\section{KEYWORDS}

anthropogenic pressures, climate, connectance, generalism, human impacts, pollination networks, richness, sampling effects, specialization 


\section{1 | INTRODUCTION}

Pollination networks, describing mutualistic interactions between plants and pollinators, are of particular importance for ecosystem functioning and services (Potts et al., 2010). Animal pollination is essential in the origin and the maintenance of wild plant diversity (Bascompte \& Jordano, 2007; Grimaldi, 1999), with about $90 \%$ of angiosperm species depending on it for reproduction (Ollerton et al., 2011). It is also crucial for agriculture as $35 \%$ of crop production may come from animal-pollinated species (Klein et al., 2007; but see Aizen et al., 2009). There is a raising concern over a global pollination crisis as we observe a parallel decline of insect pollinators and their associated plants (Biesmeijer et al., 2006; IPBES, 2016; Potts et al., 2016), affecting particularly specialist species (Redhead et al., 2018; Weiner et al., 2014), and threatening ecosystem functioning, food security, and human well-being (IPBES, 2016; Potts et al., 2016). The richness of pollination networks, as well as their structure evaluated through their levels of generalism and nestedness, is predicted to affect greatly their vulnerability to perturbations (Jiang et al., 2019; Lever et al., 2014; Thébault \& Fontaine, 2010; Valdovinos et al., 2018). In this context, understanding how natural and anthropogenic environmental factors determine the richness and structure of pollination networks at a global scale, and in particular their levels of generalism vs. specialization, appears critical (Elle et al., 2012; Potts et al., 2010, 2016).

Historically, geographic patterns of changes in diversity and generalism/specialization have been mostly related to latitudinal and climatic gradients. Productive and stable climatic conditions in the tropics are expected to favor diversity (Pianka, 1966) and specialization (Optimal Foraging Theory [OFT]; MacArthur \& Pianka, 1966), as found for various taxa (Dyer et al., 2007; Forister et al., 2015; Gainsbury \& Meiri, 2017; Peguero et al., 2017). However, recent studies on interaction networks between plants and pollinators have shown ambiguous results on this issue. The richness of plants and flower visitors in pollination networks does not appear related with latitude or any other associated climatic variables (Trøjelsgaard \& Olesen, 2013). In addition, while Trøjelsgaard and Olesen (2013) found the number of links per plant species to be maximum at mid-latitudes, Schleuning et al. (2012) reported higher generalism in tropical than in temperate environments. Other results suggested that these relations depend on the hemisphere (Pauw \& Stanway, 2015) as well as on the climatic variables and the network-related measures of generalism/specialization considered (e.g., Trøjelsgaard \& Olesen, 2013). For instance, studies have reported opposite effects of precipitation levels on pollinator richness in restricted climatic gradients (Martín González et al., 2009; Petanidou et al., 2018) and on network measures associated with specialization (Dalsgaard et al., 2013; Souza et al., 2018; Takemoto et al., 2014; Trøjelsgaard \& Olesen, 2013). These idiosyncratic findings might also partly result from changes in the composition of pollinator communities, with some pollinator groups having different climatic niches. Indeed, bees tend to be associated to warm and dry climate, whereas dipterans associated with colder and wetter ones (Arroyo et al., 1985; Devoto et al., 2005; Elberling \& Olesen, 1999; Kearns, 1992). In the light of those contrasting results, global climatic effects on pollination networks richness and levels of generalism remain to be clarified, especially in the context of climate change (Hegland et al., 2009; Settele et al., 2016).

While global patterns of generalism/specialization of pollination networks have been mainly studied in relation to latitude and associated climatic variables, human-related impacts might also drive changes in network structure at a global scale (Potts et al., 2010). The "Specialization-disturbance hypothesis" (Vázquez \& Simberloff, 2002) indeed predicts higher sensitivity of specialist species to anthropogenic pressures since they rely on fewer partners for their survival (Den Boer, 1968), and thus are more sensitive to secondary extinction cascades (Dunne et al., 2002). Several main components of human impacts, such as habitat loss and fragmentation, land-use conversion, and agriculture intensification, have been shown to affect negatively pollinator richness (Aizen \& Feinsinger, 2003; Burkle et al., 2013; De Palma et al., 2016; Ricketts et al., 2008; Winfree et al., 2009) and favor generalists toward specialists (Aizen et al., 2012; Albrecht et al., 2014; Redhead et al., 2018; Spiesman \& Inouye, 2013; Weiner et al., 2014). Yet, other aspects of human impacts can have more complex effects. For instance, moderate levels of urbanization can be associated with positive effects on pollinator diversity (Wenzel et al., 2020). Similarly, habitat heterogeneity due to land use changes has also been associated with positive effects on beta-diversity (Carré et al., 2009; Quintero et al., 2009; Winfree et al., 2008). It is clear that anthropogenic disturbances affect the diversity and structure of pollination networks; however, how these effects combine and translate at a global scale remains unclear. A recent study suggested a link between human impacts and higher nestedness and lower modularity in mutualistic networks all around the world (Takemoto \& Kajihara, 2016). Our aim is to move one step further and to investigate how effects of anthropogenic pressures rank compared to climatic effects in shaping biogeographical patterns in pollination network structure at a global scale.

For such a global synthetic analysis of pollination network structure along envrionmental and human impact gradients, a major challenge lies in accounting for the heterogeneity in survey design and sampling effort (SE) that may mask biological phenomena (Pellissier et al., 2018). Sampling methods strongly affect network diversity and structure. First, the SE, proportional to individual hours of sampling, influences directly the completness of the survey, and is expected to be linked with higher records of richness and generalism (Blüthgen et al., 2008; Dormann et al., 2009; Rivera-Hutinel et al., 2012). Second, the temporal extent of annual sampling (hereafter, annual time span [ATS]) also affects the completeness of the survey by increasing both richness and species generalism (Schwarz et al., 2020). However, surveys with wide time span also produce an increase in records of forbidden links (sensu Olesen et al., 2011) due to temporal uncoupling of species, and therefore display lower levels of network 
connectance (Schwarz et al., 2020). Third, the sampling method (i.e., timed-observations per plant species vs. transect or random sampling) affects the evenness of observation effort among species and thus network properties (Gibson et al., 2011). Fourth, sampled networks can also vary in their taxonomic resolution. Low degree of taxonomic resolution can obscure real richness and increase measurements of generalism when species are lumped into morphospecies or units of higher taxonomic rank (Renaud et al., 2020). Finally, the intercorrelation between species richness (i.e., network size) and connectance or link densities (i.e., mean number of interactions per species in each guild; Dormann et al., 2009), found in numerous studies (Jordano, 1987; Olesen \& Jordano, 2002; Thébault \& Fontaine, 2010), is likely driven not only by differences in SEs but also by altered specialization due to modified diversity of potential resources and competitors (Winemiller et al., 2001). For instance, the size of the available partner pool must be accounted to reveal differences in relative specialization levels rather than imposed specialization in depauperate environments (Armbruster, 2017). Altogether, it seems crucial to incroporate all these potential sampling and size effects in large-scale comparative studies of pollination networks.

In this study, we aimed to investigate the relative effects of (1) anthropogenic pressures, synthetized with the human influence index (HII) derived from the Human Footprint map (Venter et al., 2016); and (2) climate, described as local temperature and precipitation means and seasonality, in shaping the richness and levels of generalism of real-world pollination networks of flowering plants and their insect visitors at the global scale. Parallely, we explored the need to account for (3) heterogeneity in sampling design as these methodological aspects can hinder meaningfull comparisons and mask biologically significant patterns in such global analyses. For that purpose, we analyzed a dataset of 295 networks from all scientific litterature available to our knowledge which provided at least a full list of interactions and extensive information on sampling characteristics. We tested a series of hypotheses based on an extensive review of ecological theories associated with pollination network richness and levels of generalism (Table S1). In particular, we explored whether (1) human disturbances extirpate species and more particularly specialist species through habitat degradation, or on the contrary, promote diversity by shaping more heterogeneous landscapes and facilitating biotic invasions. We investigated (2) underlying bioclimatic gradients shaping organism distributions according to insect and plant physiological requirements, climatic stability (diversity-stability theory; Pianka, 1966), and resources availability (OFT; MacArthur \& Pianka, 1966). In conjunction, we examined a set of hypotheses dealing with (3) statistical interrelations of network attributes and sampling methods. Analyses were carried out for community-wide networks, as well as sub-networks limited to dipteran and hymenopteran pollinators since different group of pollinators have been shown to differ in their level of generalism (Weiner et al., 2011), and their responses to anthropogenic pressures (Biesmeijer et al., 2006; Weiner et al., 2014) and climate (Martín González et al., 2009).

\section{2 | MATERIALS AND METHODS}

\subsection{Collection and selection of networks}

We gathered data on plant-insect pollination networks from an extensive search in scientific literature. The criteria for a network to be included in our database were the following: (1) the sampling of insect flower visitors should not be restricted to particular taxa but should include all insect flower visitors; (2) the network should include a minimum of five plant species, five insect species, and 10 interactions; and (3) information on SE, time span, and method should be provided. Our database included 295 networks from 92 publications encompassing 11,088 insect species, 4027 plant species, and 54,716 interactions (Supporting Information S2). These networks were spread across all continents except Antarctica, and various continental and oceanic islands, covering a wide latitudinal $\left(43,10^{\circ} \mathrm{S}-81,82^{\circ} \mathrm{N}\right)$ and altitudinal $(0-3700 \mathrm{~m})$ extent (Figure 1).

\subsection{Data extraction for predictive variables}

To quantify the level of anthropogenic pressures at each study site, we derived a HII from the Human Footprint map of Venter et al. (2016). This index aggregates various drivers of the human influence on ecosystems, namely population density, proximity to roads, railways, and waterways, urbanization level, light pollution, land use, and proximity to coasts. It is the most up-to-date and comprehensive map of global cumulative anthropogenic pressures available and it allows to capture in a global synthetic way the anthropogenic disruption of ecosystems. This index was available for the year 2009 with a 30 arcseconds resolution (i.e., $0.93 \times 0.93=0.86 \mathrm{~km}^{2}$ ). For our analysis, HII was scaled between 0 and 100 (Figure 1).

To estimate the climatic conditions at each study site, we extracted the annual mean temperature and total precipitation, as well as the temperature and precipitation seasonality, averaged on the 1960-1990 period, with a 30 arcseconds resolution, from the WorldClim database (www.worldclim.org, v.1.4; Hijmans et al., 2005).

To characterize the sampling design of each study, we recorded (1) the SE as the number of person-hours spent in sampling; (2) the sampling ATS as the extent of the survey in days within a year; and (3) the sampling method which can either be timed-observations per plant species, or transects/random sampling. Species timed-observations implies an equal SE among plant species while for transects and random samplings, the SE per plant species is proportional to its abundance (Gibson et al., 2011). We included timed-observations on focal plots in this last category as SE per plant also depends on plant species abundance in that case. (4) Finally, we quantified the level of taxonomic resolution as the percentage of taxa identified to species level, this to account for potential effects of taxonomic aggregation. 


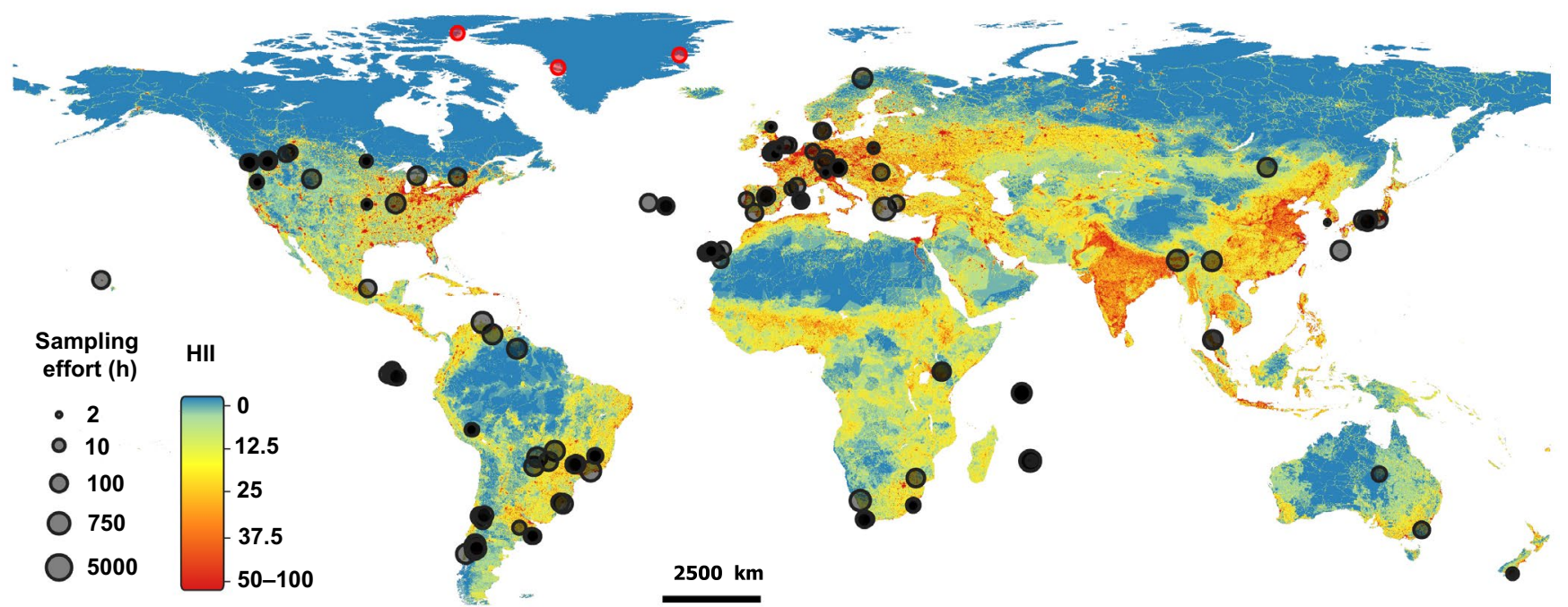

FIGURE 1 Location of the 295 pollination networks included in this study. Background color represents anthropogenic pressures on ecosystems measured as the human influence index (HII) derived from Venter et al. (2016). Point size is proportional to the sampling effort in person-hours. Darker points relate to the overlap of close sampled sites. Red points represent three arctic networks excluded post-hoc from analyses due to their inconsiderate statistical weights (see Supporting Information S5)

\subsection{Aggregation of network sites}

To avoid over-representation of studies presenting numerous networks sampled in nearby sites, and prevent pseudo-replication (Schleuning et al., 2012), we aggregated networks from a study when sampling sites were less than $50 \mathrm{~km}$ apart (Hung et al., 2018). We also expect this method to tackle spatial-scaling issues arising when comparing networks with different sampling area (Galiana et al., 2018). We did not merge network sites from different publications since their sampling methods could differ. We also kept separated networks in sites from different islands, or from different habitats when mentioned explicitly by the authors. Finally, we did not merge networks from studies explicitly claiming to study differences among networks along environmental gradient. For aggregated networks, we averaged the geographic coordinates, HII, and climatic variables, and we summed SE and merged sampling ATS among aggregated sites. We obtained a working dataset of 123 aggregated networks (see Supporting Information S2 for complete list with data).

\section{4 | Statistical analyses}

To assess the relative effects of (1) anthropogenic pressures, (2) climate, and (3) sampling design on plant-insect flower visitor networks, we modeled the relationships between a set of nine and 10 predictors describing those three factors, and a set of six response variables characterizing the richness and the structure, as the levels of generalism, of our networks.

Network richness was measured as insect $\left(S_{1}\right)$, plant $\left(S_{p}\right)$, and total $\left(S_{\text {tot }}\right)$ number of species. We estimated the levels of generalism by computing the link density of insects $\left(L_{1}\right)$ and plants $\left(L_{P}\right)$ as the average number of links per species (Dormann et al., 2009; Warren, 1994), and the network connectance (C) as the proportion of realized interactions (Jordano, 1987). We computed directly our response variables from the interaction lists of aggregated networks, then we applied log-transformations to approach normal distributions.

The predictors were as follows: (1) the HII, depicting anthropogenic pressures; $(2)$ the annual total precipitation levels $\left(P_{\text {tot }}\right)$ in $\mathrm{mm}$; (3) the mean temperature $\left(T_{\text {mean }}\right)$ in ${ }^{\circ} \mathrm{C}$; (4) the seasonality of precipitation $\left(P_{\mathrm{var}}\right)$ calculated as coefficient of variation among months; (5) the temperature seasonality $\left(T_{\text {var }}\right)$ in ${ }^{\circ} \mathrm{C}$, calculated as standard deviation among months, depicting climatic effects; (6) the SE as person-hours spent in sampling, or its standardized version (stdSE), divided by the number of potential interactions, when analyzing connectance and link densities; (7) the ATS of sampling; (8) the sampling method (i.e., timed-observations equally apportioned among plants species vs. transect or random sampling); (9) the taxonomic resolution as the proportion of taxa identified to species level; and additionally (10) the network size $\left(S_{\text {tot }}\right)$ or partner pool $\left(S_{1}\right.$ or $\left.S_{p}\right)$ only for models of connectance and link densities, respectively, to account for network size-effects. HII, SE, and ATS were log-transformed. All response variables and predictors were scaled prior to the modeling to obtain standardized beta-coefficients.

In total, we fitted three sets of linear multiple regression models for each response variable: one set for community-wide networks, and two sets for sub-networks restricted to respectively dipteran pollinators and hymenopteran pollinators, to highlight possible differential responses among taxa.

We took into account the potential spatial auto-correlation among study sites using spatial eigenvector filtering (SEVF; Dray et al., 2006; Griffith \& Peres-Neto, 2006) with a neighboring distance 
threshold of $150 \mathrm{~km}$ drawn from correlogram analyses with the $\mathrm{R}$ package ncf 1.1-7 (Bjornstad, 2016). Only SEVs that reduced best the spatial autocorrelation in the residuals were incorporated as spatial filters in our models with the R package spdep 1.1-2 (Bivand et al., 2013), ensuring the final residuals demonstrated no signs of autocorrelation (i.e., Moran's I were non-significant based on permutation tests with 10,000 iterations).

Additionally, we applied a multimodel averaging framework (Burnham \& Anderson, 2002; Diniz-Filho et al., 2008) implemented in the R package MuMln 1.42.1 (Barton, 2018) to weight the estimated coefficients and associated $p$ values among collection of minimum adequate models (MAMs; $\triangle \mathrm{AICc} \leq 2$ compared to the best model). We reported the importance of each predictor as the sum of Akaike weights ( $\Sigma w_{i}$; Symonds \& Moussalli, 2011). We considered each predictor with a $\Sigma w_{i}>0.8$ to be important (e.g., Martín González et al., 2015; Sebastián-González et al., 2015).

We decided to remove the three arctic networks from our dataset since they showed extreme residuals and high Cook's distances. Indeed, they presented outlier values in both HII, and climatic conditions, which tended to drive our statistical analyses with the risk of introducing a strong bias. Results of analyses including the arctic networks are available in Supporting Information S5.

The raw network interaction data that support the findings of this study are publicly available at https://doi.org/10.5281/ zenodo.4300427. All R scripts and aggregated network data used to carry out the analyses and draw the figures in the R 3.6.2 environment (R Core Team, 2019) are accessible here: https://github.com/ MaelDore/Pollination_networks.

\section{3 | RESULTS}

Sampling design displayed stronger effects on both pollination networks richness and levels of generalism than anthropogenic pressures or climate. Sampling variables presented significant effects on all our response variables, with high variable importances (mostly $=1.00$ ), and the highest beta-coefficients in our models (Tables 1 and 2). In comparison, anthropogenic pressures showed significant effects on the levels of generalism in our networks, but not on richness, and with a lower intensity than most sampling

TAB LE 1 Variable importance and standardized coefficients for models of network richness in community-wide networks. The parameter associated with sampling method models the relative effect of species timed-observation samplings vs. transect or random samplings as base level. Significant coefficients $(p<0.05)$ are reported in bold. Number of asterisks indicates the level of significance based on the $p$ value associated with the estimated parameters such as ${ }^{*} p<0.05 ;{ }^{* *} p<0.01 ;{ }^{* * *} p<0.001$. NS = not-significant in the case of Moran's indices.

$\sum w_{i}=$ Variable importance evaluated as the sum of Akaike weights. $\sum w_{i}>0.8$ are highlighted in bold. MAM= minimum adequate models with $\Delta \mathrm{AICc} \leq 2$. Number of MAMs: a: two; b: one; c: two

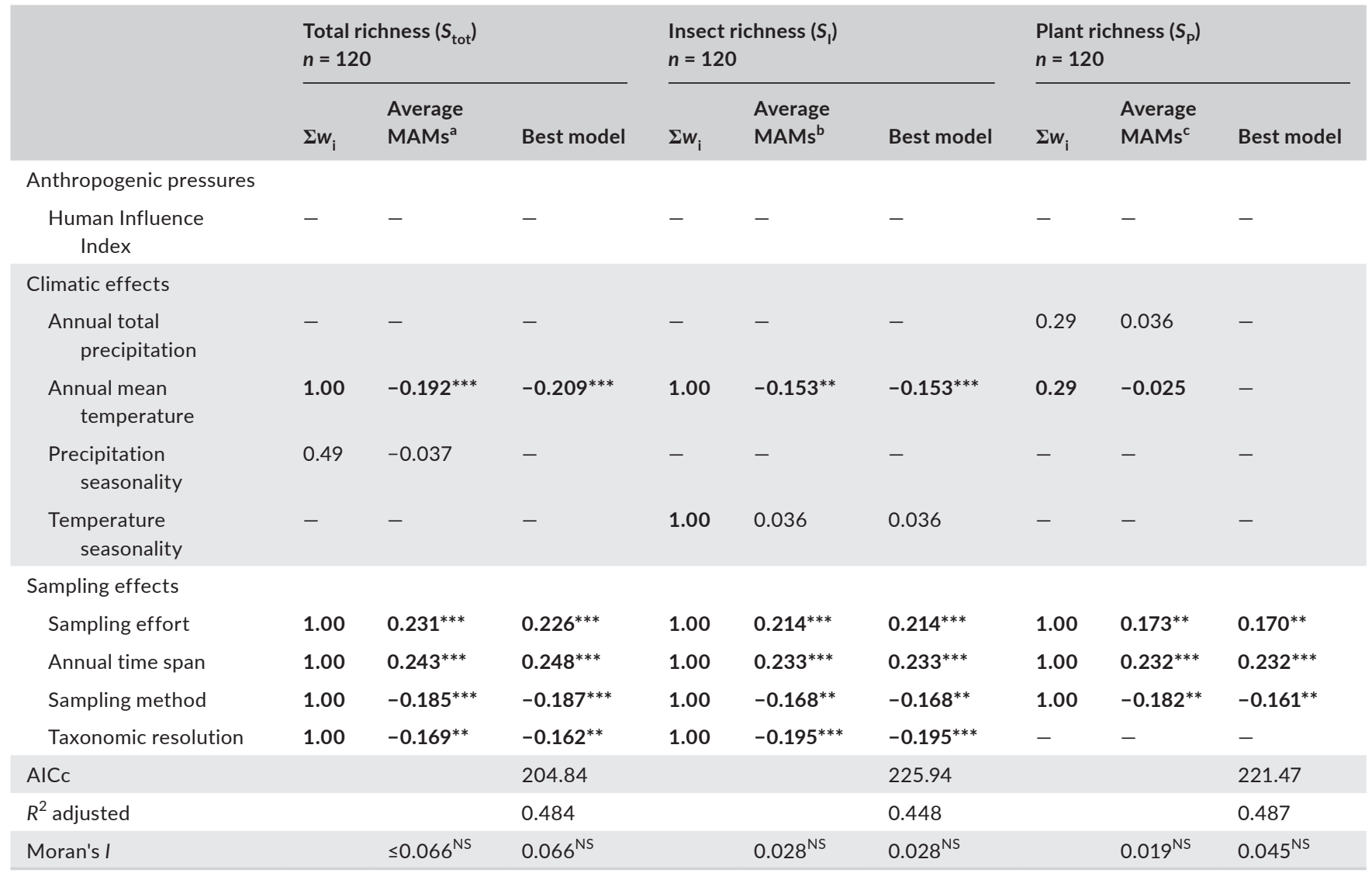


TABLE 2 Variable importance and standardized coefficients for models of network structure, as levels of generalism, in community-wide networks. The parameter associated with sampling method models the relative effect of species timed-observation samplings vs. transect or random samplings as base level. Significant coefficients $(p<0.05)$ are reported in bold. Number of asterisks indicates the level of significance based on the $p$ value associated with the estimated parameters such as ${ }^{*} p<0.05 ;{ }^{* *} p<0.01 ;{ }^{* * *} p<0.001$. NS = not-significant in the case of Moran's indices. $\sum w_{i}=$ Variable importance evaluated as the sum of Akaike weights. $\sum w_{i}>0.8$ are highlighted in bold. $M A M=$ minimum adequate models with $\triangle \mathrm{AICc} \leq 2$. Number of MAMs: a: eight; b: eight; c: eight

\begin{tabular}{|c|c|c|c|c|c|c|c|c|c|}
\hline & \multicolumn{3}{|c|}{$\begin{array}{l}\text { Connectance }(C) \\
n=120\end{array}$} & \multicolumn{3}{|c|}{$\begin{array}{l}\text { Insect link density }\left(L_{1}\right) \\
n=120\end{array}$} & \multicolumn{3}{|c|}{$\begin{array}{l}\text { Plant link density }\left(L_{P}\right) \\
n=120\end{array}$} \\
\hline & $\Sigma w_{i}$ & $\begin{array}{l}\text { Average } \\
\text { MAMs }^{\mathrm{a}}\end{array}$ & Best model & $\Sigma w_{i}$ & $\begin{array}{l}\text { Average } \\
\text { MAMs }^{\mathrm{b}}\end{array}$ & $\begin{array}{l}\text { Best } \\
\text { model }\end{array}$ & $\Sigma w_{i}$ & $\begin{array}{l}\text { Average } \\
\text { MAMs }^{c}\end{array}$ & $\begin{array}{l}\text { Best } \\
\text { model }\end{array}$ \\
\hline \multicolumn{10}{|l|}{ Anthropogenic pressures } \\
\hline $\begin{array}{l}\text { Human Influence } \\
\text { Index }\end{array}$ & 0.90 & 0.059 & 0.062 & 0.88 & 0.049 & $0.060^{*}$ & 1.00 & $0.086^{*}$ & $0.088^{*}$ \\
\hline $\begin{array}{l}\text { Annual total } \\
\text { precipitation }\end{array}$ & - & -0.007 & - & 0.37 & 0.008 & 0.021 & 0.62 & -0.036 & -0.057 \\
\hline $\begin{array}{l}\text { Annual mean } \\
\text { temperature }\end{array}$ & 0.35 & -0.016 & - & - & - & - & 0.39 & -0.021 & -0.055 \\
\hline \multicolumn{10}{|l|}{ Sampling effects } \\
\hline $\begin{array}{l}\text { Network size } \\
\qquad\left(S_{P}+S_{I}=S_{\text {tot }}\right)\end{array}$ & 1.00 & $-0.218^{* * *}$ & $-0.220^{* * *}$ & NA & NA & NA & NA & NA & NA \\
\hline Partner pool $\left(S_{P}\right.$ or $\left.S_{l}\right)$ & NA & NA & NA & 1.00 & $0.231^{* * *}$ & $0.221^{* * *}$ & 1.00 & $0.393^{* * *}$ & $0.398^{* * *}$ \\
\hline $\begin{array}{l}\text { Standardized } \\
\text { sampling effort }\end{array}$ & 1.00 & $0.142^{* * *}$ & $0.142^{* * *}$ & 1.00 & $0.119^{* * *}$ & $0.118^{* * *}$ & 1.00 & $0.215^{* * *}$ & $0.220^{* * *}$ \\
\hline Annual time span & 1.00 & $-0.132^{* * *}$ & $-0.133^{* * *}$ & 1.00 & $-0.077^{* *}$ & $-0.070^{* *}$ & 1.00 & $-0.196^{* * *}$ & $-0.182^{* *}$ \\
\hline Sampling method & 1.00 & $0.089^{* *}$ & $0.090^{* *}$ & 0.43 & 0.022 & - & 1.00 & $0.095^{* *}$ & 0.094 \\
\hline Taxonomic resolution & 0.09 & 0.002 & - & 1.00 & 0.056 & 0.042 & 0.14 & 0.004 & - \\
\hline
\end{tabular}

variables (Tables 1 and 2). Besides, climatic variables revealed to have no significant effect on network structure and richness, with the exception of the negative effect of mean temperature on species richness mainly driven by dipteran pollinators and their interacting plants (Tables 1 and 2; Table S4.1.1).

\section{1 | Effects of anthropogenic pressures on pollination networks}

We detected no significant effect of anthropogenic pressures on the species richness of community-wide pollination networks, neither for insect richness (Figure S3.1.1a), plant richness (Figure S3.1.2a) nor total richness (Figure 2a). Indeed, the HII was not retained as a predictor in any of the best models and even MAMs for richness (Table 1). Similarly, no significant effects were found in neither dipteran nor hymenopteran sub-networks (Tables S4.1.1 and S4.1.2; Figure 2a; Figures S3.1.1a and S3.1.2a).
The increase in human influence on ecosystems leads to higher levels of generalism in community-wide pollination networks. We detected a tendency for a positive relationship between HII and connectance associated with high variable importance (Table 2; Figure 2b). Complementarily, the link density of both pollinators (Table 2; Figure S3.1.1b) and plants (Table 2; Figure S3.1.2b) increases alongside the gradient of anthropogenic pressures. These effects are mainly driven by hymenopterans, as the trends are absent in the dipteran sub-networks (Tables S4.2.1 and S4.2.2; Figure 2b; Figures S3.1.1b and S3.1.2b).

\subsection{Effects of climate on pollination networks}

Only the annual mean temperature demonstrated a significant effect on the species richness of community-wide pollination networks: low temperatures appeared to be linked with a higher total species richness (Table 1; Figure 3a), and a higher insect species richness (Table 1; Figure S3.2.1a). However, this effect was found 

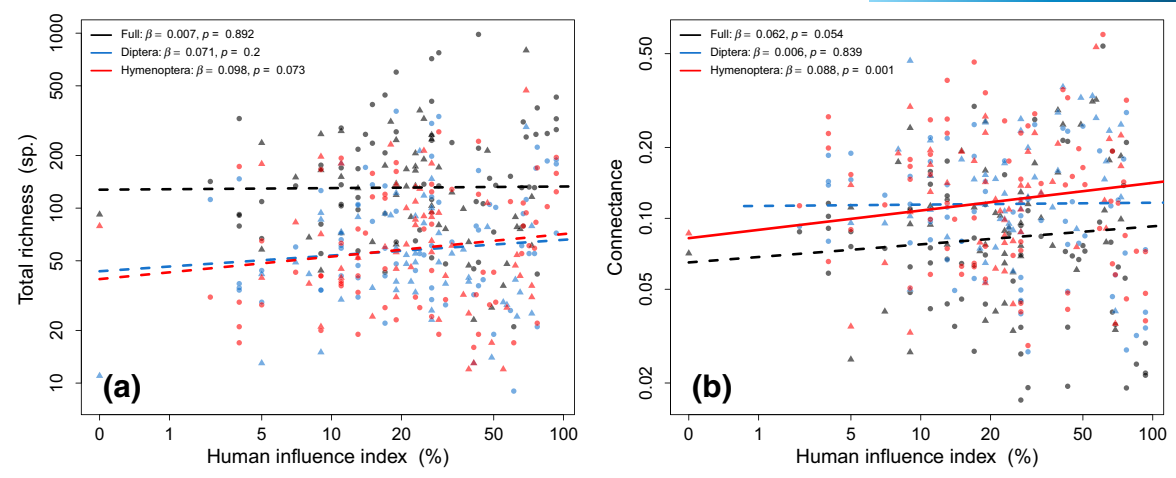

FIGURE 2 Effects of anthropogenic pressures, characterized by the human influence index, on pollination network species richness (a) and connectance (b) for community-wide networks (black), dipteran sub-networks (blue), and hymenopteran sub-networks (red). Point shape relates to the sampling method: dots = transects or random samplings, triangles = species timed-observations. Lines represent predicts of the best model including the human influence index, when all other variables are set to their observed average. Lines are solid when the coefficient associated to the slope differs significantly from zero $(p<0.05)$ and dashed when it is not $(p \geq 0.05)$. All axes are on log scale
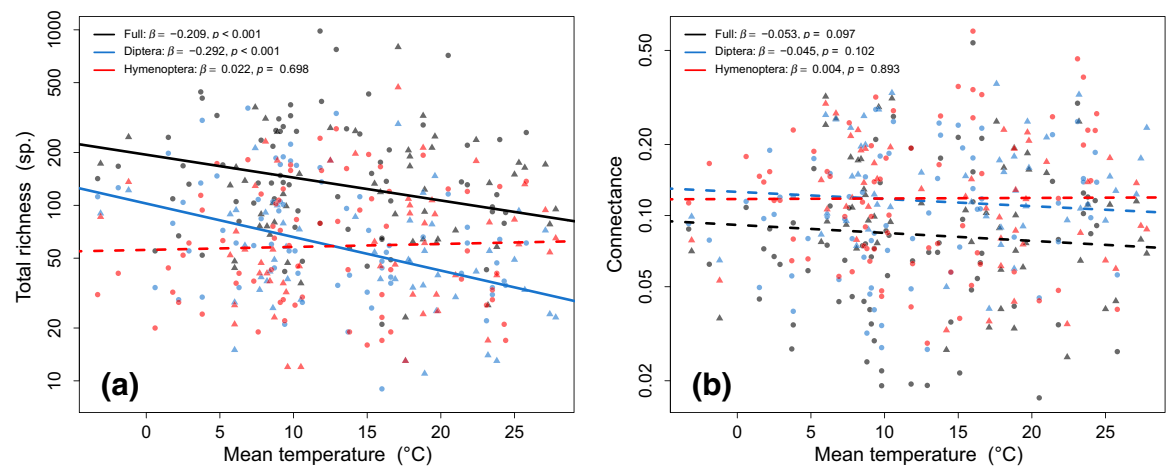

FIGURE 3 Effects of annual mean temperature on species richness (a) and pollination network connectance (b) and for communitywide networks (black), dipteran sub-networks (blue), and hymenopteran sub-networks (red). Point shape relates to the sampling method: dots = transects or random samplings, triangles = species timed-observations. Lines represent predicts of the best model including the annual mean temperature, when all other variables are set to their observed average. Lines are solid when the coefficient associated with the slope differs significantly from zero $(p<0.05)$ and dashed when it is not $(p \geq 0.05)$. $Y$-axes are on log scale

in dipteran sub-networks (Table S4.2.1; Figure 3a; Figures S3.2.1a and S3.2.2a), but not in hymenopteran sub-networks (Table S4.1.2; Figure 3a; Figures S3.2.1a and S3.2.2a). In contrast, hymenopteran sub-networks exhibit an increase in their total and insect species richness with temperature seasonality (Table S4.1.2).

We found limited effects of climate on the generalism of pollination networks. No significant effect of climate variables was detected in our average MAMs and best models of network connectance and link densities (Table 2; Figure 3b). No significant effect was detected for any sub-network neither (Tables S4.2.1 and S4.2.2; Figure 3b; Figures S3.2.1b and S3.2.2b), except a decrease in insect link density with annual total precipitation in hymenopteran sub-networks (Table S4.2.2).

\section{3 | Sampling and size effects in pollination networks}

Sampling design displayed stronger effects than anthropogenic pressures or climate on both the richness and generalism of pollination networks. Sampling variables showed strong and consistent effects on most of our measurements of network richness and levels of generalism in community-wide networks, with high variable importance (mostly $=1.00$ ), and the highest beta-coefficients in our models (Tables 1 and 2). When detected, dipteran and hymenopteran sub-networks showed similar responses to sampling design.

All richness measurements increased with SE (Table 1; Tables S4.1.1 and S4.1.2; Figure 4a; Figures S3.3.1a and S3.3.2a). Similarly, ATS of sampling demonstrated a positive effect on all richness indices (Table 1; Tables S4.1.1 and S4.1.2). Community-wide networks and embedded dipteran sub-networks investigated under species timed-observation sampling recorded lower richness values than those studied with transects or random sampling (Table 1; Table S4.1.1). Conversely, hymenopteran sub-networks did not show effects of sampling methods on their total and insect richness (Table S4.1.2). Total richness decreased with taxonomic resolution in community-wide networks and hymenopteran sub-networks (Table 1; Table S4.1.2; Figure 4c). Insect richness demonstrated the same negative trend (Table 1; Table S4.1.2; Figure S3.3.1c), but not plant richness (Table 1; Table S4.1.2; Figure S3.3.2c). Meanwhile, dipteran 

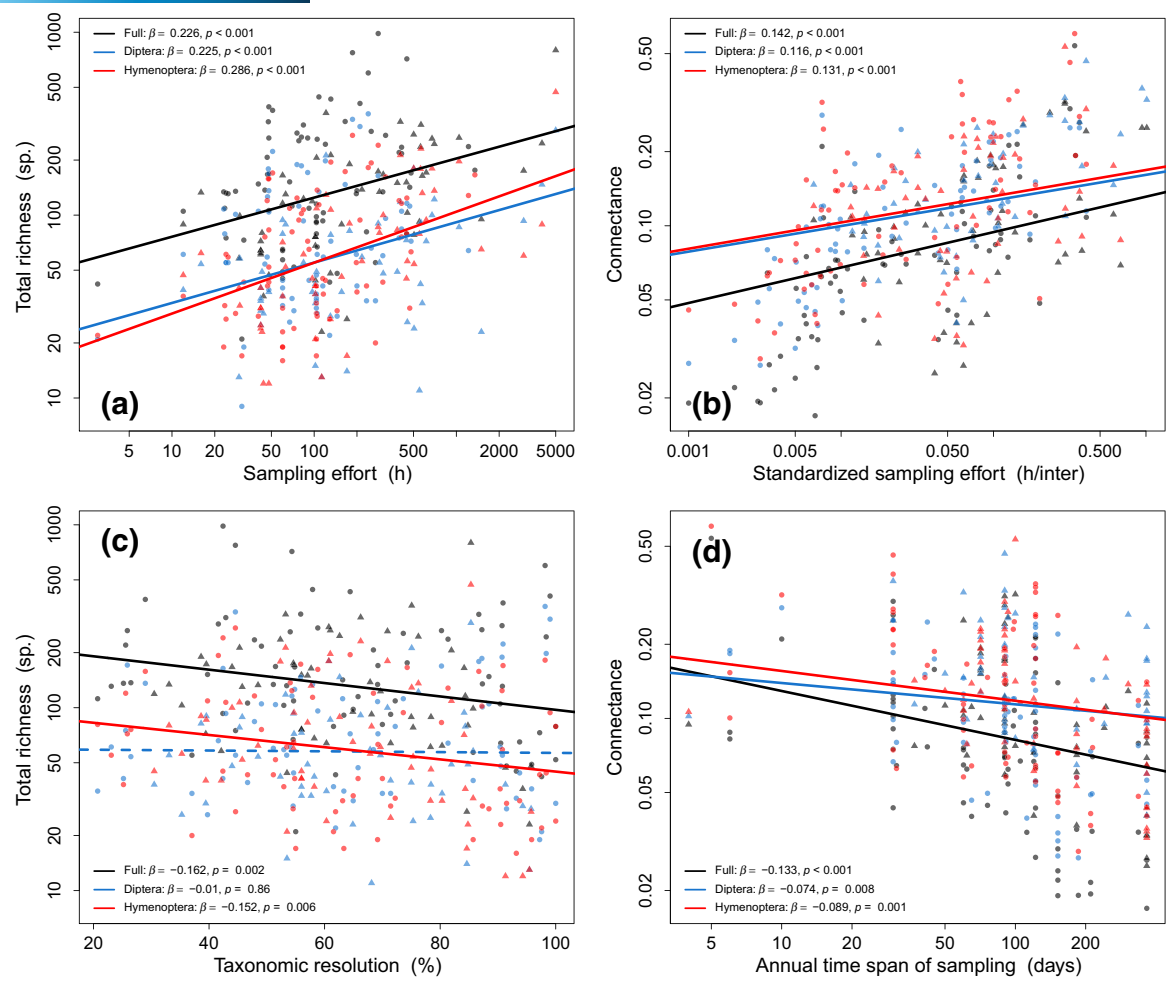

FIGURE 4 Effects of sampling design on pollination network species richness (a, c) and connectance (b, d) for community-wide networks (black), dipteran sub-networks (blue), and hymenopteran sub-networks (red). (a) Effect of sampling effort on species richness. (b) Effect of sampling effort, standardized by the number of potential interactions, on network connectance. (c) Effect of taxonomic resolution on species richness. (d) Effect of annual time span of sampling on network connectance. Point shape relates to the sampling method: dots $=$ transects or random samplings, triangles = species timed-observations. Lines represent predicts of the best model including the predictor, when all other variables are set to their observed average. Lines are solid when the coefficient associated with the slope differs significantly from zero $(p<0.05)$ and dashed when it is not $(p \geq 0.05)$. All $Y$-axes and $X$-axes for sampling effort, standardized sampling effort, and annual time span of sampling are on log-scale

sub-networks showed no effect of taxonomic resolution on any richness indices (Table S4.1.1; Figure 4c; Figures S3.3.1c and S3.3.2c).

Network size (i.e., number of species) had preponderant effects on our measurements of network structure. It was the main predictor of connectance in community-wide pollination networks with a strong significant negative effect (Table 2). Likewise, the size of the partner pool was the main predictor of insect and plant link densities (Table 2). We found similar strong size effects in dipteran and hymenopteran sub-networks (Tables S4.2.1 and S4.2.2).

Sampling design also widely influenced our measurements of generalism in community-wide networks. Connectance and link densities increased with the SE (Table 2; Figure 4b; Figures S3.3.1b and S3.3.2b). In contrast, all those metrics scored lower in networks with wider sampling ATS (Table 2; Figure 4d, Figures S3.3.1d and S3.3.2d). Species timed-observation sampling methods were associated with higher network connectance and higher plant link densities than transect or random sampling (Table 2). We found no significant effect of taxonomic resolution on connectance and link densities (Table 2). Altogether, effects on dipteran and hymenopteran sub-networks were fairly similar. However, they showed weaker responses to the sampling method (Tables S4.2.1 and S4.2.2). We also found an additional positive effect of taxonomic resolution on insect link density in hymenopteran sub-networks (Table S4.2.2; Figure S3.3.1c).

\section{4 | DISCUSSION}

Our study reveals that levels of generalism in pollination networks, measured as connectance and insect and plant link densities, increase with human influence on ecosystems, whereas diversity is slightly related with climate through a negative correlation between mean annual temperature and species richness driven by dipteran pollinators. These results support some of our initial hypotheses (Table S1) and also highlight contrasting responses between dipteran and hymenopteran sub-networks. In addition, we showed that sampling design displayed the strongest effects on both pollination network structure and richness. It stresses the need to consider sampling heterogeneity in studies analyzing interaction networks coming from different origins and sampling methods.

\subsection{Generalism increases with anthropogenic pressures in pollination networks}

Our results highlight that anthropogenic disturbances, as synthesized by the HII, affect the structure of plant-pollinator networks, increasing network connectance, and link densities worldwide. Our study thus generalizes at a global scale a pattern observed locally 
by previous studies focusing on specific type of disturbances (Aizen et al., 2012; Burkle et al., 2013; Redhead et al., 2018; Spiesman \& Inouye, 2013; Steffan-Dewenter et al., 2006). Several mechanisms could explain the higher generalism in anthropogenic habitats. First, specialist species might be replaced by generalist species in anthropogenic habitats. Specialist species depend on a more restricted set of partners for survival (specialization-disturbance theory; Vázquez \& Simberloff, 2002) and are thus more susceptible to cascade of secondary extinctions (Dunne et al., 2002). On the other hand, generalist species are expected to be more flexible and resistant to environmental changes according to niche theory (Clavel et al., 2011). Second, anthropogenic habitats are also more likely to host invasive, introduced or managed species that show higher generalism than native plant and insect species (Aizen et al., 2008; Albrecht et al., 2014; Geslin et al., 2017; Stouffer et al., 2014). Lastly, species might also enlarge their niche to include more interacting partners in anthropogenic habitats characterized by higher risks of extinction, as predicted by Den Boer's theory (1968).

However, sensitivity to human impacts may also depend on the taxa considered. Our analyses suggest the structure of subnetworks involving only hymenopterans is more affected by anthropogenic pressures than that of sub-networks involving dipterans, reflecting what has been found previously for species diversity in Germany (Weiner et al., 2014) and the Netherlands (Biesmeijer et al., 2006). Indeed, effects of pollinator turn-over and diet enlargement could be stronger in hymenopteran sub-networks that host highly specialized taxa among solitary bees and wasps (Janzen, 1979; Linsley, 1958; Weiner et al., 2011, 2014), predicted to be more sensitive to anthropogenic pressures. Those findings point out the need to include all pollinator groups in pollination network studies (Orford et al., 2015) since their responses to anthropogenic pressures can differ among them and from community-wide patterns.

Our results further show that anthropogenic perturbations can affect network structure without having a detectable effect on species richness. Indeed, we found no significant relationship between HII and the richness of pollinators, plants or both combined. Landuse intensification associated with habitat fragmentation trigger extinctions of native plants and pollinators (Aguilar et al., 2006; Aizen et al., 2012; Burkle et al., 2013; Ricketts et al., 2008; Weiner et al., 2014; Winfree et al., 2009) while agrochemicals are suspected to affect negatively pollinators (IPBES, 2016; Potts et al., 2016). However, intermediate levels of anthropogenic disturbances can also increase pollinator and plant richness by providing diverse landscape of habitats (Carré et al., 2009; Vanbergen et al., 2017; Wenzel et al., 2020; Winfree et al., 2007, 2008). Moreover, local richness of disturbed habitats can increase due to the presence of invasive species that compensate the loss of native ones (Aizen et al., 2008; Stouffer et al., 2014). Therefore, the combination of these opposing mechanisms might explain the absence of effect of anthropogenic pressures on pollination network richness in our analysis. This result stresses the importance of evaluating network structure to fully assess the impact of anthropogenic pressures on ecological communities (Filippi-Codaccioni et al., 2010; Tylianakis et al., 2010).
Higher generalism could have consequences on pollination function as it might decrease pollination effectiveness by increasing pollen loss in interspecific exchanges and interference of foreign pollen on the stigmata (Aizen \& Feinsinger, 2003; Armbruster, 2006). Changes in network structure could influence the stability of plant-insect communities. A community dominated by generalists is expected to promote community persistence and robustness to secondary extinctions (Dunne et al., 2002; Memmott et al., 2004; Thébault \& Fontaine, 2010, but see Vieira \& Almeida-Neto, 2015), preventing ecological breakdown (Jiang et al., 2019; Lever et al., 2014). Finally, eco-evolutionary dynamics of pollinators and their associated flowering plants could be affected. On the long term, specialists may sustain higher diversification rate via hostshift leading quickly to reproductive isolation (Armbruster, 2014; Johnson \& Steiner, 2000; Kay \& Sargent, 2009). To the contrary, generalists are expected to influence the convergent evolution of many species while they are less likely to respond to evolutionary shift of one of their many partners (Guimarães et al., 2011). Thus, loss of specialist species could represent the loss of unique ecological interactions and co-evolutionary pathways (Aizen et al., 2012).

\subsection{Climate affects richness and composition of pollination networks}

In contrast with the anthropogenic impacts, climate did not show consistent effects on pollination network structure, but revealed few contrasted effects on richness that could have consequences in the context of climate change.

The OFT predicts greater specialization and diversity in steady, predictable and productive environments such as the ones found in the wet and hot Tropics, for both pollinators and plants. Indeed, plants are also expected to benefit from specialization toward the most efficient pollinator when its presence is predictable and reliable (Stebbin's principle; Johnson \& Steiner, 2000; Stebbins, 1970; Waser et al., 1996). However, we found no effect of climate and its variability on network connectance, link densities, and flowering plant richness, but a trend for higher pollinator richness in cooler environments. The absence of higher specialization in productive environments associated with high precipitation and temperature levels might be explained by the dilution of potential resources and partners of each species in the local biodiversity, thus providing a patchy environment despite the local richness, and switching the expectation from the OFT toward generalism. This paradox could explain previous contrasting results on modularity and niche partitioning (Dalsgaard et al., 2013; Takemoto et al., 2014 vs. Schleuning et al., 2012), and the absence of clear effects highlighted in our study. In parallel, the expected trend for higher levels of generalism in unstable environments could be underpinned by an increase in the number of forbidden links (sensu Olesen et al., 2011) due to a lack of overlap between species phenologies as seasonal climate might favor different groups of species along the year. 
The absence of relation between plant richness and climatic variables contrasts with previous findings on global patterns of plant diversity, which show that water- and energy-related variables are main predictors of plant richness (species-energy theory, Wright, 1983; water-energy dynamics hypothesis, Hawkins et al., 2003). Our result might be related to our focus on local communities because climatic-related latitudinal patterns of diversity appear stronger when diversity is considered at regional scale rather than local scale (Hillebrand, 2004). In addition, we considered a subset of plant diversity that is the diversity of flowering plants visited by insects. In our case, observed plant diversity is thus partly related to pollinators. This is exemplified by the increase of plant richness in dipteran sub-networks in cooler environments, which parallels the trend observed for the richness of dipteran pollinators.

The surprising increase in pollinator richness in cooler environments casts light on the differential responses to climate between taxonomic groups. Indeed, this result was driven by the increase in dipteran pollinator richness while hymenopterans showed no response to annual mean temperature (Figure 3a; Tables S4.1.1and S4.1.2). The higher richness of dipteran pollinators in cooler climates is a known pattern (Arroyo et al., 1985; Devoto et al., 2005; Elberling \& Olesen, 1999; Kearns, 1992; Medan et al., 2002; Totland, 1993), explained by their low energetic requirements for flying and their ability for thermoregulation via sun-basking in heliotropic flowers (Arroyo et al., 1985; Kearns, 1990, 1992). Other climatic effects were only detected at the sub-network level. For dipteran sub-networks, pollinator richness decreased with the seasonality of precipitation (Table S4.1.1). In contrast, we found an increase in total richness with temperature seasonality in hymenopteran networks (Table S4.1.2), which might be explained by a wider availability of thermic niches along the year, reducing competition, thereby enhancing richness. These contrasting responses of pollinator groups to climate, but also anthropogenic pressures, suggest that global changes could have important consequences on the composition of pollinator communities in the future. It also recalls that not all taxa are equal in the face of global changes, and is a reminder that we should always be cautious about generalizations that may over or underestimate human impacts on ecological communities.

\subsection{Sampling and size effects are ubiquitous and preponderant}

Our study highlighted the need to account for the effects of sampling design when analyzing network data from heterogeneous sources, as they had the strongest effects on the properties of pollination networks.

We first retrieved two well-known relations typically included in comparative network analyses: a strong negative relationship between connectance and network size (Jordano, 1987; Olesen \& Jordano, 2002; Thébault \& Fontaine, 2010), and a positive correlation between the SE and the number of interactions and species recorded (Dalsgaard et al., 2017; Fründ et al., 2016; Traveset et al., 2016; Vizentin-Bugoni et al., 2014; Zanata et al., 2017).

Second, our study highlighted three other important sampling effects associated with ATS of sampling, sampling methods, and taxonomic resolution, typically overlooked in comparative network analyses. We revealed the ATS of sampling could have strong effects on network richness and generalism, as found by a recent study (Schwarz et al., 2020). Richness indices increased significantly with the ATS of sampling since a wider span allows to better sample the turn-over of species along the seasons. Singularly, we reported a decrease in connectance and link densities with increasing ATS of sampling, which was not detected by previous studies taking this factor into consideration (Dalsgaard et al., 2011, 2017; Schleuning et al., 2012; but see Schwarz et al., 2020). Indeed, a wider ATS of sampling should induce the presence of more forbidden links (sensu Jordano, 2016; Olesen et al., 2011) due to lack of overlap between species phenologies. We further showed that the method of sampling influences network metrics at the global scale: we found species timed-observations sampling allows to detect less species, but more interactions per species than transects or random sampling, extending results of a local case study (Gibson et al., 2011). Lastly, taxonomic resolution was negatively related to richness, especially for hymenopteran (Table 1; Figure 4c; Figure S3.3.1c), and had no effect on connectance and link densities (Table 2). Such higher richness associated with lower taxonomic resolution was contrary to our expectations (Table S1). This could indicate that researchers tend to split rather to lump species when defining morpho-species, or conversely that highly resolved networks actually hide certain level of accidental species aggregation. It could also simply suggest that insect species from rich environments, especially hymenopterans, are less known and less easily identified.

Altogether, not taking into consideration the heterogeneity of sampling design among networks, even for typically overlooked sampling characteristics, can lead to drastically different results and conclusions. For instance, disregarding potential sampling effects, we could not detect the increase in generalism associated with human impacts, neither the negative effect of annual mean temperature on total and insect species richness (Supporting Information S6).

\section{4 | Methodological shortcomings}

Despite our concern to include the effects of sampling heterogeneity in our analysis, several issues remain. In particular, a large proportion of the networks included in our dataset lacked quantitative information on the strength and/or frequency of interactions. Thus, to maximize the coverage of our study, we focused only on metrics for binary networks. A step forward would be to refine evaluation of specialization using weighted metrics less prone to sampling heterogeneity and sizeeffects (Blüthgen et al., 2006; Dormann et al., 2009).

In parallel, the mapping of networks included in our study highlighted spatial heterogeneity in the location of pollination network 
surveys worldwide (Figure 1). Several regions such as polar regions, Africa, Central Asia, and the Tropics in general, remain largely undersampled. This could be an important bias for macroecological analyses. First, ecological responses of pollination networks can vary between regions and biomes (Archer et al., 2014; De Palma et al., 2016). Second, network sites in undersampled regions could bear inconsiderate weights in the analyses, especially if they illustrate extreme conditions, as shown with the arctic networks in this study (Supporting Information S5).

\section{5 | Conclusion}

Our study revealed anthropogenic pressures globally correlate with an increase in generalism in pollination networks while species richness and broad taxonomic composition of pollinators are weakly related to climate. Such effects of anthropogenic pressures could result in a decrease in the ecosystem pollination function and losses of unique ecological interactions and evolutionary pathways, but further research is needed to better evaluate these potential consequences. Our research also highlighted the importance of the network approach when studying ecological responses to anthropogenic pressures since their effects were detected only at the network structure level. We recorded differential responses of pollinator groups to climate and anthropogenic pressures at the global scale that could have important consequences on pollinator community composition in the context of global changes. Indeed, dipteran pollinators appeared less sensitive to anthropogenic pressures than hymenopterans, and seem to thrive in cooler climates. Altogether, we showed sampling design, rather than anthropogenic pressures and climate, mainly explained the variation in pollination network properties. In addition to network size and SE, we showed sampling method, temporal extent of annual sampling, and taxonomic resolution can affect network measurements. Our results stress the need to report such characteristics in pollination surveys, and to incorporate them in macroecological studies synthesizing data from multiple sources to reveal biologically significant patterns at the global scale. Finally, our extensive review of available data on pollination networks calls for a SE in previously neglected regions to extend the scope of future research.

\section{ACKNOWLEDGEMENTS}

We gratefully thank all researchers, field workers, technicians, students, etc., that were involved in the collection, analysis, and publication of the many interaction networks we were able to gather and analyze for this study, and for making their data publicly available. We also thank O. Adedoja, K. Baldock, C. Olito, and Y-H Zhao for kindly providing additional data on their sampling effort. This study contains data supplied by Natural Environment Research Council. The authors certify that they have no affiliations with or involvement in any organization or entity with any financial interest, or non-financial interest in the subject matter or materials discussed in this manuscript. M.D. is financed by the French Ministry of Research
(MENSR), and E.T. and C.F. were funded by the ANR projects ARSENIC (ANR-14-CE02-0012) \& ECONET (ANR-18-CE02-0010).

\section{AUTHOR CONTRIBUTIONS}

Maël Doré led the manuscript writing. Maël Doré, Colin Fontaine, and Elisa Thébault conceived the ideas, retrieved, and interpreted the data. Maël Doré designed and carried out the analyses. All authors critically contributed to the manuscript draft and gave final approval for publication.

\section{DATA AVAILABILITY STATEMENT}

The raw network interaction data that support the findings of this study are publicly available at https://doi.org/10.5281/zenodo.4300427. All $\mathrm{R}$ scripts and aggregated network data used to carry out the analyses and draw the figures in the R 3.6.2 environment ( $R$ Core Team, 2019) are openly available at https://github.com/MaelDore/Polli nation_networks.

\section{ORCID}

Maël Doré (D) https://orcid.org/0000-0003-3242-9242

\section{REFERENCES}

Aguilar, R., Ashworth, L., Galetto, L., \& Aizen, M. A. (2006). Plant reproductive susceptibility to habitat fragmentation: Review and synthesis through a meta-analysis. Ecology Letters, 9(8), 968-980. https:// doi.org/10.1111/j.1461-0248.2006.00927.x

Aizen, M. A., \& Feinsinger, P. (2003). Bees not to be? Responses of insect pollinator faunas and flower pollination to habitat fragmentation. In How landscapes change (pp. 111-129). Springer. https://doi. org/10.1007/978-3-662-05238-9_7

Aizen, M. A., Garibaldi, L. A., Cunningham, S. A., \& Klein, A. M. (2009). How much does agriculture depend on pollinators? Lessons from long-term trends in crop production. Annals of Botany, 103(9), 1579-1588. https://doi.org/10.1093/aob/mcp076

Aizen, M. A., Morales, C. L., \& Morales, J. M. (2008). Invasive mutualists erode native pollination webs. PLoS Biology, 6(2), 396-403. https:// doi.org/10.1371/journal.pbio.0060031

Aizen, M. A., Sabatino, M., \& Tylianakis, J. M. (2012). Specialization and rarity predict nonrandom loss of interactions from mutualist networks. Science, 335(6075), 1486-1489. https://doi.org/10.1126/ science. 1215320

Albrecht, M., Padrón, B., Bartomeus, I., \& Traveset, A. (2014). Consequences of plant invasions on compartmentalization and species' roles in plant-pollinator networks. Proceedings of the Royal Society B: Biological Sciences, 281(1788). https://doi.org/10.1098/ rspb.2014.0773

Archer, C. R., Pirk, C. W. W., Carvalheiro, L. G., \& Nicolson, S. W. (2014). Economic and ecological implications of geographic bias in pollinator ecology in the light of pollinator declines. Oikos, 123(4), 401-407. https://doi.org/10.1111/j.1600-0706.2013.00 949.x

Armbruster, W. S. (2006). Evolutionary and ecological aspects of specialized pollination: Views from the arctics to the tropics. In N. M. Waser \& J. Ollerton (Eds.), Plant-pollinator interactions: From specialization to generalization (pp. 260-282). University of Chicago Press.

Armbruster, W. S. (2014). Floral specialization and angiosperm diversity: Phenotypic divergence, fitness trade-offs and realized pollination accuracy. AoB PLANTS, 6, 1-24. https://doi.org/10.1093/aobpla/ plu003 
Armbruster, W. S. (2017). The specialization continuum in pollination systems: Diversity of concepts and implications for ecology, evolution and conservation. Functional Ecology, 31(1), 88-100. https:// doi.org/10.1111/1365-2435.12783

Arroyo, M. T. K., Armesto, J. J., \& Primack, R. B. (1985). Community studies in pollination ecology in the high temperate Andes of central Chile. II. Effect of temperature on visitation rates and pollination possibilities. Plant Systematics and Evolution, 149(3-4), 187-203. https://doi.org/10.1007/BF00983305

Barton, K. (2018). MuMIn: Multi-Model Inference (R package version 1.42.1). Retrieved from https://cran.r-project.org/package=MuMIn

Bascompte, J., \& Jordano, P. (2007). Plant-animal mutualistic networks: The architecture of biodiversity. Annual Review of Ecology, Evolution, and Systematics, 38(1), 567-593. https://doi.org/10.1146/annur ev.ecolsys.38.091206.095818

Biesmeijer, J. C., Roberts, S. P. M., Reemer, M., Ohlemüller, R., Edwards, M., Peeters, T., Schaffers, A. P., Potts, S. G., Kleukers, R., Thomas, C. D., Settele, J., \& Kunin, W. E. (2006). Parallel declines in pollinators and insect-pollinated plants in Britain and the Netherlands. Science, 313(5785), 351-354. https://doi.org/10.1126/science. 1127863

Bivand, R. S., Pebesma, E., \& Gomez-Rubio, V. (2013). Applied spatial data analysis with $R$ (2nd ed.). Springer. Retrieved from http://www.asdarbook.org/

Bjornstad, O. N. (2016). ncf: Spatial nonparametric covariance functions (R package version 1.1-7). Retrieved from https://cran.r-proje ct.org $/$ package $=$ ncf

Blüthgen, N., Fründ, J., Vazquez, D. P., \& Menzel, F. (2008). What do interaction network metrics tell us about specialization and biological traits? Ecology, 89(12), 3387-3399. https://doi.org/10.1890/ 07-2121.1

Blüthgen, N., Menzel, F., \& Blüthgen, N. (2006). Measuring specialization in species interaction networks. BMC Ecology, 6(9). https://doi. org/10.1186/1472-6785-6-9

Burkle, L. A., Marlin, J. C., \& Knight, T. M. (2013). Plant-pollinator interactions over 120 years: Loss of species, co-occurrence, and function. Science, 340(6127), 1611-1615. https://doi.org/10.1126/scien ce.1232728

Burnham, K. P., \& Anderson, D. R. (2002). Model selection and multimodel inference: A practical information-theoretic approach (2nd ed.). Springer. https://doi.org/10.1007/b97636

Carré, G., Roche, P., Chifflet, R., Morison, N., Bommarco, R., HarrisonCripps, J., Krewenka, K., Potts, S. G., Roberts, S. P. M., Rodet, G., Settele, J., Steffan-Dewenter, I., Szentgyörgyi, H., Tscheulin, T., Westphal, C., Woyciechowski, M., \& Vaissière, B. E. (2009). Landscape context and habitat type as drivers of bee diversity in European annual crops. Agriculture, Ecosystems and Environment, 133(1-2), 40-47. https://doi.org/10.1016/j.agee.2009.05.001

Clavel, J., Julliard, R., \& Devictor, V. (2011). Worldwide decline of specialist species: Toward a global functional homogenization? Frontiers in Ecology and the Environment, 9(4), 222-228. https://doi.org/10.1890/ 080216

Dalsgaard, B., Magård, E., Fjeldså, J., González, A. M. M., Rahbek, C., Olesen, J. M., Ollerton, J., Alarcón, R., Araujo, A. C., Cotton, P. A., Lara, C., Machado, C. G., Sazima, I., Sazima, M., Timmermann, A., Watts, S., Sandel, B., Sutherland, W. J., \& Svenning, J. C. (2011). Specialization in plant-hummingbird networks is associated with species richness, contemporary precipitation and quaternary climate-change velocity. PLoS One, 6(10). https://doi.org/10.1371/ journal.pone.0025891

Dalsgaard, B., Schleuning, M., Maruyama, P. K., Dehling, D. M., Sonne, J., Vizentin-Bugoni, J., Zanata, T. B., Fjeldså, J., Böhning-Gaese, K., \& Rahbek, C. (2017). Opposed latitudinal patterns of network-derived and dietary specialization in avian plant-frugivore interaction systems. Ecography, 40(12), 1395-1401. https://doi.org/10.1111/ ecog.02604
Dalsgaard, B., Trøjelsgaard, K., Martín González, A. M., Nogués-Bravo, D., Ollerton, J., Petanidou, T., Sandel, B., Schleuning, M., Wang, Z., Rahbek, C., Sutherland, W. J., Svenning, J. C., \& Olesen, J. M. (2013). Historical climate-change influences modularity and nestedness of pollination networks. Ecography, 36(12), 1331-1340. https://doi. org/10.1111/j.1600-0587.2013.00201.x

De Palma, A., Abrahamczyk, S., Aizen, M. A., Albrecht, M., Basset, Y., Bates, A., Blake, R. J., Boutin, C., Bugter, R., Connop, S., Cruz-López, L., Cunningham, S. A., Darvill, B., Diekötter, T., Dorn, S., Downing, N., Entling, M. H., Farwig, N., Felicioli, A., ... Purvis, A. (2016). Predicting bee community responses to land-use changes: Effects of geographic and taxonomic biases. Scientific Reports, 6(July), 1-14. https://doi.org/10.1038/srep31153

Den Boer, P. J. (1968). Spreading of risk and stabilization of animal numbers. Acta Biotheoretica, 18(1-4), 165-194. https://doi.org/10.1007/ BF01556726

Devoto, M., Medan, D., \& Montaldo, N. H. (2005). Patterns of interaction between plants and pollinators along an environmental gradient. Oikos, 109(3), 461-472. https://doi.org/10.1111/j.0030-1299. 2005.13712.x

Diniz-Filho, J. A. F., Rangel, T. F. L. V. B., \& Bini, L. M. (2008). Model selection and information theory in geographical ecology. Global Ecology and Biogeography, 17(4), 479-488. https://doi.org/10.1111/j.14668238.2008.00395.x

Dormann, C. F., Frund, J., Bluthgen, N., \& Gruber, B. (2009). Indices, graphs and null models: Analyzing bipartite ecological networks. The Open Ecology Journal, 2(1), 7-24. https://doi.org/10.2174/18742 13000902010007

Dray, S., Legendre, P., \& Peres-Neto, P. R. (2006). Spatial modelling: A comprehensive framework for principal coordinate analysis of neighbour matrices (PCNM). Ecological Modelling, 196(3-4), 483493. https://doi.org/10.1016/j.ecolmodel.2006.02.015

Dunne,J.A.,Williams, R.J., \& Martinez, N.D. (2002). Networkstructureand biodiversity loss in food webs: Robustness increases with connectance. Ecology Letters, 5(4), 558-567. https://doi.org/10.1046/j.14610248.2002.00354.x

Dyer, L. A., Singer, M. S., Lill, J. T., Stireman, J. O., Gentry, G. L., Marquis, R. J., Ricklefs, R. E., Greeney, H. F., Wagner, D. L., Morais, H. C., Diniz, I. R., Kursar, T. A., \& Coley, P. D. (2007). Host specificity of Lepidoptera in tropical and temperate forests. Nature, 448(7154), 696-699. https://doi.org/10.1038/nature05884

Elberling, H., \& Olesen, J. (1999). The structure of a high latitude plantflower visitor system: The dominance of flies. Ecography, 22(3), 314-323. https://doi.org/10.1111/j.1600-0587.1999.tb00507.x

Elle, E., Elwell, S. L., \& Gielens, G. A. (2012). The use of pollination networks in conservation. Botany, 90(7), 525-534. https://doi. org/10.1139/B11-111

Filippi-Codaccioni, O., Devictor, V., Bas, Y., \& Julliard, R. (2010). Toward more concern for specialisation and less for species diversity in conserving farmland biodiversity. Biological Conservation, 143(6), 1493-1500. https://doi.org/10.1016/j.biocon.2010.03.031

Forister, M. L., Novotny, V., Panorska, A. K., Baje, L., Basset, Y., Butterill, P. T., Cizek, L., Coley, P. D., Dem, F., Diniz, I. R., Drozd, P., Fox, M., Glassmire, A. E., Hazen, R., Hrcek, J., Jahner, J. P., Kaman, O., Kozubowski, T. J., Kursar, T. A., ... Dyer, L. A. (2015). The global distribution of diet breadth in insect herbivores. Proceedings of the National Academy of Sciences of the United States of America, 112(2), 442-447. https://doi.org/10.1073/pnas.1423 042112

Fründ, J., Mccann, K. S., \& Williams, N. M. (2016). Sampling bias is a challenge for quantifying specialization and network structure: Lessons from a quantitative niche model. Oikos, 125(4), 502-513. https:// doi.org/10.1111/oik.02256

Gainsbury, A., \& Meiri, S. (2017). The latitudinal diversity gradient and interspecific competition: No global relationship between lizard dietary niche breadth and species richness. Global Ecology 
and Biogeography, 26(5), 563-572. https://doi.org/10.1111/geb. 12560

Galiana, N., Lurgi, M., Claramunt-López, B., Fortin, M. J., Leroux, S., Cazelles, K., Gravel, D., \& Montoya, J. M. (2018). The spatial scaling of species interaction networks. Nature Ecology and Evolution, 2(5), 782-790. https://doi.org/10.1038/s41559-018-0517-3

Geslin, B., Gauzens, B., Baude, M., Dajoz, I., Fontaine, C., Henry, M., Ropars, L., Rollin, O., Thébault, E., \& Vereecken, N. J. (2017) Massively Introduced Managed Species and Their Consequences for Plant-Pollinator Interactions. Advances in Ecological Research, 57, 147-199. https://doi.org/10.1016/bs.aecr.2016.10.007

Gibson, R.H., Knott,B., Eberlein, T.,\&Memmott,J.(2011).Samplingmethod influences the structure of plant-pollinator networks. Oikos, 120(6), 822-831. https://doi.org/10.1111/j.1600-0706.2010.18927.x

Griffith, D. A., \& Peres-Neto, P. R. (2006). Spatial modeling in ecology: The flexibility of eigenfunction spatial analyses. Ecology, 87(10), 2603-2613. https://doi.org/10.1890/0012-9658(2006)87\%5B260 3:SMIETF\%5D2.0.CO;2

Grimaldi, D. (1999). The co-radiations of pollinating insects and angiosperms in the cretaceous. Annals of the Missouri Botanical Garden, 86(2), 373. https://doi.org/10.2307/2666181

Guimarães, P. R., Jordano, P., \& Thompson, J. N. (2011). Evolution and coevolution in mutualistic networks. Ecology Letters, 14(9), 877-885. https://doi.org/10.1111/j.1461-0248.2011.01649.x

Hawkins, B. A., Field, R., Cornell, H. V., Currie, D. J., Guégan, J. F., Kaufman, D. M., Kerr, J. T., Mittelbach, G. G., Oberdorff, T., O'Brien, E. M., Porter, E. E., \& Turner, J. R. G. (2003). Energy, water, and broad-scale geographic patterns of species richness. Ecology, 84(12), 3105-3117. https://doi.org/10.1890/03-8006

Hegland,S.J.,Nielsen,A.,Lázaro,A.,Bjerknes,A.L.,\&Totland,Ø.(2009).How does climate warming affect plant-pollinator interactions? Ecology Letters, 12(2), 184-195. https://doi.org/10.1111/j.1461-0248.2008. 01269.x

Hijmans, R. J., Cameron, S. E., Parra, J. L., Jones, P. G., \& Jarvis, A. (2005). Very high resolution interpolated climate surfaces for global land areas. International Journal of Climatology, 25(15), 1965-1978. https:// doi.org/10.1002/joc.1276

Hillebrand, H. (2004). On the generality of the latitudinal diversity gradient. American Naturalist, 163(2), 192-211. https://doi. org/10.1086/381004

Hung, K.-L. J., Kingston, J. M., Albrecht, M., Holway, D. A., \& Kohn, J. R. (2018). The worldwide importance of honey bees as pollinators in natural habitats. Proceedings of the Royal Society B: Biological Sciences, 285(1870), 2017-2140. https://doi.org/10.1098/rspb.2017.2140

IPBES. (2016). The assessment report of the Intergovernmental SciencePolicy Platform on Biodiversity and Ecosystem Services on pollinators, pollination and food production (S. G. Potts, V. L. Imperatriz-Fonseca, $\&$ H. T. Ngo, Eds.). Retrieved from www.IPBES.net

Janzen, D. H. (1979). How to be a figure. Annual Review of Ecology and Systematics, 10(1), 13-51. https://doi.org/10.1146/annurev. es.10.110179.000305

Jiang, J., Hastings, A., \& Lai, Y. C. (2019). Harnessing tipping points in complex ecological networks. Journal of the Royal Society Interface, 16(158). https://doi.org/10.1098/rsif.2019.0345

Johnson, S. D., \& Steiner, K. E. (2000). Generalization versus specialization in plant pollination systems. Trends in Ecology \& Evolution, 15(4), 140-143. https://doi.org/10.1016/S0169-5347(99)01811-X

Jordano, P. (1987). Patterns of mutualistic interactions in pollination and seed dispersal: Connectance, dependence asymmetries, and coevolution. The American Naturalist, 129(5), 657-677. https://doi. org/10.1086/284665

Jordano, P. (2016). Sampling networks of ecological interactions. Functional Ecology, 30(12), 1883-1893. https://doi.org/10.1111/ 1365-2435.12763

Kay, K. M., \& Sargent, R. D. (2009). The role of animal pollination in plant speciation: Integrating ecology, geography, and genetics. Annual
Review of Ecology, Evolution, and Systematics, 40(1), 637-656. https://doi.org/10.1146/annurev.ecolsys.110308.120310

Kearns, C. A. (1990). The role of fly pollination in montane habitats. PhD thesis, University of Maryland.

Kearns, C. A. (1992). Anthophilous fly distribution across an elevation gradient. The American Midland Naturalist, 127(1), 172-182. https:// doi.org/10.2307/2426332

Klein, A. M., Vaissière, B. E., Cane, J. H., Steffan-Dewenter, I., Cunningham, S. A., Kremen, C., \& Tscharntke, T. (2007). Importance of pollinators in changing landscapes for world crops. Proceedings of the Royal Society B: Biological Sciences, 274(1608), 303-313. https:// doi.org/10.1098/rspb.2006.3721

Lever, J. J., van Nes, E. H., Scheffer, M., \& Bascompte, J. (2014). The sudden collapse of pollinator communities. Ecology Letters, 17(3), 350-359. https://doi.org/10.1111/ele.12236

Linsley, E. G. (1958). The ecology of solitary bees. Hilgardia, 27(19), 543599. https://doi.org/10.3733/hilg.v27n19p543

MacArthur, R. H., \& Pianka, E. R. (1966). On optimal use of a patchy environment. The American Naturalist, 100(916), 603-609. https://doi. org/10.1086/282454

Martín González, A. M., Dalsgaard, B. O., Nogués-Bravo, D., Graham, C. H., Schleuning, M., Maruyama, P. K., Abrahamczyk, S., Alarcón, R., Araujo, A. C., Araújo, F. P., de Azevedo, S. M., Baquero, A. C., Cotton, P. A., Ingversen, T. T., Kohler, G., Lara, C., Las-Casas, F. M. G., Machado, A. O., Machado, C. G., ... Martinez, N. D. (2015). The macroecology of phylogenetically structured hummingbird-plant networks. Global Ecology and Biogeography, 24(11), 1212-1224. https://doi.org/10.1111/geb.12355

Martín González, A. M., Dalsgaard, B., Ollerton, J., Timmermann, A., Olesen, J. M., Andersen, L., \& Tossas, A. G. (2009). Effects of climate on pollination networks in the West Indies. Journal of Tropical Ecology, 25(5), 493-506. https://doi.org/10.1017/S026646740999 0034

Medan, D., Montaldo, N. H., Devoto, M., Mantese, A., Vasellati, V., Roitman, G. G., \& Bartoloni, N. H. (2002). Plant-pollinator relationships at two altitudes in the Andes of Mendoza, Argentina. Arctic, Antarctic, and Alpine Research, 34(3), 233. https://doi.org/ 10.2307/1552480

Memmott, J., Waser, N. M., \& Price, M. V. (2004). Tolerance of pollination networks to species extinctions. Proceedings of the Royal Society B: Biological Sciences, 271(1557), 2605-2611. https://doi. org/10.1080/01496395.2011.625388

Olesen, J. M., Bascompte, J., Dupont, Y. L., Elberling, H., Rasmussen, C., \& Jordano, P. (2011). Missing and forbidden links in mutualistic networks. Proceedings of the Royal Society B: Biological Sciences, 278(1706), 725-732. https://doi.org/10.1098/rspb.2010.1371

Olesen, J. M., \& Jordano, P. (2002). Geographic patterns in plant-pollinator mutualistic networks. Ecology, 83(9), 2416-2424. https://doi.org/ 10.1890/0012-9658(2002)083\%5B2416:GPIPPM\%5D2.0.CO;2

Ollerton, J., Winfree, R., \& Tarrant, S. (2011). How many flowering plants are pollinated by animals? Oikos, 120(3), 321-326. https://doi. org/10.1111/j.1600-0706.2010.18644.x

Orford, K. A., Vaughan, I. P., \& Memmott, J. (2015). The forgotten flies: The importance of non-syrphid Diptera as pollinators. Proceedings of the Royal Society B: Biological Sciences, 282(1805). https://doi. org/10.1098/rspb.2014.2934

Pauw, A., \& Stanway, R. (2015). Unrivalled specialization in a pollination network from South Africa reveals that specialization increases with latitude only in the Southern Hemisphere. Journal of Biogeography, 42(4), 652-661. https://doi.org/10.1111/jbi.12453

Peguero, G., Bonal, R., Sol, D., Muñoz, A., Sork, V. L., \& Espelta, J. M. (2017). Tropical insect diversity: Evidence of greater host specialization in seed-feeding weevils. Ecology, 98(8), 2180-2190. https:// doi.org/10.1002/ecy.1910

Pellissier, L., Albouy, C., Bascompte, J., Farwig, N., Graham, C., Loreau, M., Maglianesi, M. A., Melián, C. J., Pitteloud, C., Roslin, T., Rohr, 
R., Saavedra, S., Thuiller, W., Woodward, G., Zimmermann, N. E., \& Gravel, D. (2018). Comparing species interaction networks along environmental gradients. Biological Reviews, 93(2), 785-800. https://doi.org/10.1111/brv.12366

Petanidou, T., Kallimanis, A. S., Lazarina, M., Tscheulin, T., Devalez, J., Stefanaki, A., Hanlidou, E., Vujić, A., Kaloveloni, A., \& Sgardelis, S. P. (2018). Climate drives plant-pollinator interactions even along small-scale climate gradients: The case of the Aegean. Plant Biology, 20, 176-183. https://doi.org/10.1111/plb.12593

Pianka, E. R. (1966). Latitudinal gradients in species diversity: A review of concepts. The American Naturalist, 100(910), 33-46. https://doi. org $/ 10.1086 / 282398$

Potts, S. G., Biesmeijer, J. C., Kremen, C., Neumann, P., Schweiger, O., \& Kunin, W. E. (2010). Global pollinator declines: Trends, impacts and drivers. Trends in Ecology \& Evolution, 25(6), 345-353. https://doi. org/10.1016/j.tree.2010.01.007

Potts, S. G., Imperatriz-Fonseca, V., Ngo, H. T., Aizen, M. A., Biesmeijer, J. C., Breeze, T. D., Dicks, L. V., Garibaldi, L. A., Hill, R., Settele, J., \& Vanbergen, A. J. (2016). Safeguarding pollinators and their values to human well-being. Nature, 540(7632), 220-229. https://doi. org/10.1038/nature20588

Quintero, C., Morales, C. L., \& Aizen, M. A. (2009). Effects of anthropogenic habitat disturbance on local pollinator diversity and species turnover across a precipitation gradient. Biodiversity and Conservation, 19(1), 257-274. https://doi.org/10.1007/s10531-0099720-5

R Core Team (2019). R: A Language and Environment for Statistical Computing. $R$ Foundation for Statistical Computing. https://www. r-project.org/

Redhead, J. W., Woodcock, B. A., Pocock, M. J. O., Pywell, R. F., Vanbergen, A. J., \& Oliver, T. H. (2018). Potential landscape-scale pollinator networks across Great Britain: Structure, stability and influence of agricultural land cover. Ecology Letters, 21(12), 18211832. https://doi.org/10.1111/ele.13157

Renaud, E., Baudry, E., \& Bessa-Gomes, C. (2020). Influence of taxonomic resolution on mutualistic network properties. Ecology and Evolution, 10(7), 3248-3259. https://doi.org/10.1002/ece3.6060

Ricketts, T. H., Regetz, J., Steffan-Dewenter, I., Cunningham, S. A., Kremen, C., Bogdanski, A., Gemmill-Herren, B., Greenleaf, S. S., Klein, A. M., Mayfield, M. M., Morandin, L. A., Ochieng', A., \& Viana, B. F. (2008). Landscape effects on crop pollination services: Are there general patterns? Ecology Letters, 11(5), 499-515. https://doi. org/10.1111/j.1461-0248.2008.01157.x

Rivera-Hutinel, A., Bustamante, R. O., Marín, V. H., \& Medel, R. (2012). Effects of sampling completeness on the structure of plant-pollinator networks. Ecology, 93(7), 1593-1603. https://doi. org/10.1890/11-1803.1

Schleuning, M., Fründ, J., Klein, A.-M., Abrahamczyk, S., Alarcón, R., Albrecht, M., Andersson, G. K. S., Bazarian, S., Böhning-Gaese, K., Bommarco, R., Dalsgaard, B. O., Dehling, D. M., Gotlieb, A., Hagen, M., Hickler, T., Holzschuh, A., Kaiser-Bunbury, C. N., Kreft, H., Morris, R. J., ... Blüthgen, N. (2012). Specialization of mutualistic interaction networks decreases toward tropical latitudes. Current Biology, 22(20), 1925-1931. https://doi.org/10.1016/j.cub. 2012.08.015

Schwarz, B., Vázquez, D. P., CaraDonna, P. J., Knight, T. M., Benadi, G., Dormann, C. F., Gauzens, B., Motivans, E., Resasco, J., Blüthgen, N., Burkle, L. A., Fang, Q., Kaiser-Bunbury, C. N., Alarcón, R., Bain, J. A., Chacoff, N. P., Huang, S.-Q., LeBuhn, G., MacLeod, M., ... Fründ, J. (2020). Temporal scale-dependence of plant-pollinator networks. Oikos, 129(9), 1289-1302. https://doi.org/10.1111/ oik.07303

Sebastián-González, E., Dalsgaard, B., Sandel, B., \& Guimarães, P. R. (2015). Macroecological trends in nestedness and modularity of seed-dispersal networks: Human impact matters. Global Ecology and Biogeography, 24(3), 293-303. https://doi.org/10.1111/geb.12270
Settele, J., Bishop, J., \& Potts, S. G. (2016). Climate change impacts on pollination. Nature Plants, 2(7). https://doi.org/10.1038/NPLAN TS.2016.92

Souza, C. S., Maruyama, P. K., Aoki, C., Sigrist, M. R., Raizer, J., Gross, C. L., \& de Araujo, A. C. (2018). Temporal variation in plant-pollinator networks from seasonal tropical environments: Higher specialization when resources are scarce. Journal of Ecology, 106(6), 24092420. https://doi.org/10.1111/1365-2745.12978

Spiesman, B. J., \& Inouye, B. D. (2013). Habitat loss alters the architecture of plant-pollinator interaction networks. Ecology, 94(12), 2688-2696. https://doi.org/10.1890/13-0977.1

Stebbins, G. L. (1970). Adaptive radiation of reproductive characteristics in angiosperms, I: Pollination mechanisms. Annual Review of Ecology and Systematics, 1(1), 307-326. https://doi.org/10.1146/annur ev.es.01.110170.001515

Steffan-Dewenter, I., Klein, A.-M., Gaebele, V., Alfert, T., \& Tscharntke, T. (2006). Bee diversity and plant-pollinator interactions in fragmented landscapes. In N. M. Waser \& J. Ollerton (Eds.), Plantpollinator interactions. From specialization to generalization (Issue January, pp. 387-410). University of Chicago Press.

Stouffer, D. B., Cirtwill, A. R., \& Bascompte, J. (2014). How exotic plants integrate into pollination networks. Journal of Ecology, 102(6), 1442-1450. https://doi.org/10.1111/1365-2745.12310

Symonds, M. R. E., \& Moussalli, A. (2011). A brief guide to model selection, multimodel inference and model averaging in behavioural ecology using Akaike's information criterion. Behavioral Ecology and Sociobiology, 65(1), 13-21. https://doi.org/10.1007/s00265010-1037-6

Takemoto, K., \& Kajihara, K. (2016). Human impacts and climate change influence nestedness and modularity in food-web and mutualistic networks. PLoS One, 11(6), e0157929. https://doi.org/10.1371/ journal.pone.0157929

Takemoto, K., Kanamaru, S., \& Feng, W. (2014). Climatic seasonality may affect ecological network structure: Food webs and mutualistic networks. BioSystems, 121, 29-37. https://doi.org/10.1016/j.biosy stems.2014.06.002

Thébault, E., \& Fontaine, C. (2010). Stability of ecological communities and the architecture of mutualistic and trophic networks. Science, 329(5993), 853-856. https://doi.org/10.1126/science.1188321

Totland, O. (1993). Pollination in alpine Norway: Flowering phenology, insect visitors, and visitation rates in two plant communities. Canadian Journal of Botany, 71(8), 1072-1079. https://doi. org/10.1139/b93-124

Traveset, A., Tur, C., Trøjelsgaard, K., Heleno, R., Castro-Urgal, R., Olesen, J. M., \& Santos, A. (2016). Global patterns of mainland and insular pollination networks. Global Ecology and Biogeography, 25(7), 880-890. https://doi.org/10.1111/geb.12362

Trøjelsgaard, K., \& Olesen, J. M. (2013). Macroecology of pollination networks. Global Ecology and Biogeography, 22(2), 149-162. https://doi. org/10.1111/j.1466-8238.2012.00777.x

Tylianakis, J. M., Laliberté, E., Nielsen, A., \& Bascompte, J. (2010). Conservation of species interaction networks. Biological Conservation, 143(10), 2270-2279. https://doi.org/10.1016/j.biocon.2009.12.004

Valdovinos, F. S., Berlow, E. L., Moisset De Espanés, P., Ramos-Jiliberto, R., Vázquez, D. P., \& Martinez, N. D. (2018). Species traits and network structure predict the success and impacts of pollinator invasions. Nature Communications, 9(1), 1-8. https://doi.org/10.1038/ s41467-018-04593-y

Vanbergen, A. J., Woodcock, B. A., Heard, M. S., \& Chapman, D. S. (2017). Network size, structure and mutualism dependence affect the propensity for plant-pollinator extinction cascades. Functional Ecology, 31(6), 1285-1293. https://doi.org/10.1111/1365-2435. 12823

Vázquez, D. P., \& Simberloff, D. (2002). Ecological specialization and susceptibility to disturbance: Conjectures and refutations. The American Naturalist, 159(6), 606-623. https://doi.org/10.1086/339991 
Venter, O., Sanderson, E. W., Magrach, A., Allan, J. R., Beher, J., Jones, K. R., Possingham, H. P., Laurance, W. F., Wood, P., Fekete, B. M., Levy, M. A., \& Watson, J. E. M. (2016). Global terrestrial Human Footprint maps for 1993 and 2009. Scientific Data, 3(1), 1-10. https://doi. org/10.1038/sdata.2016.67

Vieira, M. C., \& Almeida-Neto, M. (2015). A simple stochastic model for complex coextinctions in mutualistic networks: Robustness decreases with connectance. Ecology Letters, 18(2), 144-152. https:// doi.org/10.1111/ele.12394

Vizentin-Bugoni, J., Maruyama, P. K., \& Sazima, M. (2014). Processes entangling interactions in communities: Forbidden links are more important than abundance in a hummingbird-plant network. Proceedings of the Royal Society B: Biological Sciences, 281(1780). https://doi.org/10.1098/rspb.2013.2397

Warren, P. H. (1994). Making connections in food webs. Trends in Ecology \& Evolution, 9(4), 136-141. https://doi.org/10.1016/01695347(94)90178-3

Waser, N. M., Chittka, L., Price, M. V., Williams, N. M., \& Ollerton, J. (1996). Generalization in pollination systems, and why it matters. Ecology, 77(4), 1043-1060. https://doi.org/10.2307/2265575

Weiner, C. N., Werner, M., Linsenmair, K. E., \& Blüthgen, N. (2011) Land use intensity in grasslands: Changes in biodiversity, species composition and specialisation in flower visitor networks. Basic and Applied Ecology, 12(4), 292-299. https://doi.org/10.1016/j. baae.2010.08.006

Weiner, C. N., Werner, M., Linsenmair, K. E., \& Blüthgen, N. (2014). Landuse impacts on plant-pollinator networks: Interaction strength and specialization predict pollinator declines. Ecology, 95(2), 466-474 https://doi.org/10.1890/13-0436.1

Wenzel, A., Grass, I., Belavadi, V. V., \& Tscharntke, T. (2020). How urbanization is driving pollinator diversity and pollination - A systematic review. Biological Conservation, 241, 108321. https://doi. org/10.1016/j.biocon.2019.108321

Winfree, R., Aguilar, R., Vázquez, D. P., Lebuhn, G., \& Aizen, M. A (2009). A meta-analysis of bees' responses to anthropogenic disturbance. Ecology, 90(8), 2068-2076. https://doi.org/10.1890/081245.1
Winfree, R., Griswold, T., \& Kremen, C. (2007). Effect of human disturbance on bee communities in a forested ecosystem. Conservation Biology, 21(1), 213-223. https://doi.org/10.1111/j.1523-1739.2006. 00574.x

Winfree, R., Williams, N. M., Gaines, H., Ascher, J. S., \& Kremen, C. (2008). Wild bee pollinators provide the majority of crop visitation across land-use gradients in New Jersey and Pennsylvania, USA. Journal of Applied Ecology, 45(3), 793-802. https://doi.org/10.1111/ j.1365-2664.2007.01418.x

Winemiller, K. O., Pianka, E. R., Vitt, L. J., \& Joern, A. (2001). Food web laws or niche theory? Six independent empirical tests. American Naturalist, 158(2), 193-199. https://doi.org/10.1086/321315

Wright, D. H. (1983).Species-energy theory-An extension of species-area theory. Oikos, 41(3), 496-506. https://doi.org/10.2307/3544109

Zanata, T. B., Dalsgaard, B. O., Passos, F. C., Cotton, P. A., Roper, J. J., Maruyama, P. K., Fischer, E., Schleuning, M., Martín González, A M., Vizentin-Bugoni, J., Franklin, D. C., Abrahamczyk, S., Alárcon, R., Araujo, A. C., Araújo, F. P., Azevedo-Junior, S. M. D., Baquero, A. C., Böhning-Gaese, K., Carstensen, D. W., ... Varassin, I. G. (2017). Global patterns of interaction specialization in bird-flower networks. Journal of Biogeography, 44(8), 1891-1910. https://doi. org/10.1111/jbi.13045

\section{SUPPORTING INFORMATION}

Additional supporting information may be found online in the Supporting Information section.

How to cite this article: Doré $\mathrm{M}$, Fontaine $\mathrm{C}$, Thébault $\mathrm{E}$. Relative effects of anthropogenic pressures, climate, and sampling design on the structure of pollination networks at the global scale. Glob Change Biol. 2020;00:1-15. https://doi.org/10.1111/gcb.15474 